\title{
Virulence determinants of high-pathogenic avian influenza viruses in gallinaceous poultry
}

\section{Jürgen Stech*1 \& Thomas C Mettenleiter}

IInstitute of Molecular Biology, Friedrich-Loeffler-Institut, Federal Research Institute for Animal Health, 17493 Greifswald-Insel Riems, Germany

*Author for correspondence: juergen.stech@fli.bund.de

High-pathogenic avian influenza viruses (HPAIV) cause devastating outbreaks in domestic poultry worldwide. Moreover, they repeatedly lead to severe, even fatal disease in humans, raising concerns about their pandemic potential. HPAIV have evolved from circulating low-pathogenic precursors in several independent events by spontaneous acquisition of a polybasic cleavage site in the hemagglutinin (HA) envelope protein. Remarkably, in nature, HPAIV are confined to the HA serotypes $\mathrm{H} 5$ and $\mathrm{H} 7$ from the $16 \mathrm{HA}$ serotypes known in birds. However, experimental introduction of a polybasic cleavage site into non-H5/H7 HA may result in a highly pathogenic phenotype, indicating that emergence of HPAIV with novel serotypes is conceivable, but requires further adaptation to the chicken host.

\section{High-pathogenic avian influenza viruses: a scourge of poultry \& a lurking pandemic threat}

High-pathogenic avian influenza viruses (HPAIV), formerly known as fowl plague viruses, cause devastating losses in domestic poultry worldwide. The infection of HPAIV in gallinaceous birds results in a systemic disease affecting several organs including the lungs, heart, digestive tract and CNS. Affected birds may die within 2-7 days after infection and the lethality within affected flocks may range from 70 to $100 \%$ [1-4]. The gold standard for assessing virulence is the determination of the intravenous pathogenicity index in chickens, yielding values of 1.20 and higher for HPAIV [5], although there are a few strains with high virulence after intravenous but not oculonasal administration [6]. Since no vaccine is available that disrupts infection chains with certainty [7-10], in most countries the control measures in case of an HPAIV outbreak are based on rigorous depopulation and the establishment of quarantine zones around affected holdings. Within the last 135 years, more than 40 outbreaks of HPAIV have been reported worldwide (TABLE 1) [11,101]. Moreover, repeated HPAIV infections in humans, some associated with high lethality [12-17], have raised concerns about further HPAIV adaptation to the human host sparking a novel pandemic.

\section{HPAIV differ from low-pathogenic avian strains by their polybasic hemagglutinin cleavage site \& their restriction to the hemagglutinin serotypes $\mathrm{H} 5$ \& $\mathrm{H} 7$}

In 1878, the well-known fowl plague was first recognized as a specific poultry disease and in
1955 its causative agents were demonstrated to be influenza A viruses [18,19]. Later, those highly virulent virus strains were renamed HPAIV. Influenza A viruses belong to the family Orthomyxoviridae, which also comprise the genera influenzavirus $\mathrm{B}$, influenzavirus $\mathrm{C}$, Isavirus and Thogotovirus [20]. All orthomyxoviruses carry a segmented ssRNA genome of negative polarity with different numbers of gene segments, and are mainly discriminated by different antigenicity of their nucleoproteins [21-23]. The genome of influenza A viruses consists of eight segments that are organized in ribonucleoprotein complexes (RNPs). Each RNP contains the viral RNA encased by nucleoproteins and one bound viral polymerase complex composed of three subunits, the PB2, PB1 and PA proteins. Within the virion, the eight RNPs are enclosed by the matrix protein M1 and a lipid envelope in which the three surface proteins hemagglutinin (HA), neuraminidase (NA) and the proton channel protein M2 are inserted [24].

All influenza A viruses are dependent on the cleavage of the HA precursor HA0 into the HA1 and HA2 fragments for infectivity $[25,26]$. Only after proteolytic activation is the trimeric HA able to alter its conformation at the acidic $\mathrm{pH}$ in the endosome, resulting in exposure of the $\mathrm{N}$ termini of the HA2 fragments, which contain the hydrophobic fusion peptides necessary to merge the virion envelope with the endosomal membrane during viral endocytotic entry [27-29]. This proteolytic activation depends on several proteases that are provided by the host and recognize different cleavage motifs. All human, mammalian and low-pathogenic avian

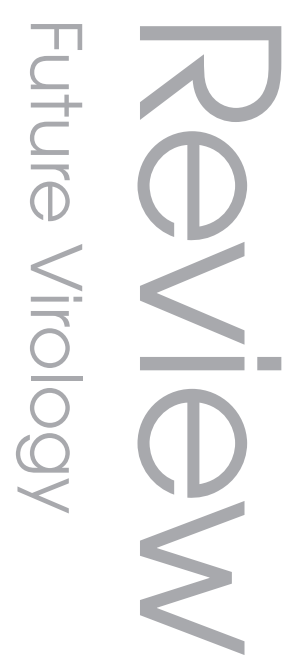

\section{Keywords}

w cleavage site w fowl plague

= H5N1 = hemagglutinin

w high-pathogenic avian

influenza virus = pathogenesis

- proteolytic activation

n virulence determinants

\section{Future
Medicine
part of}


Table 1. High-pathogenic avian influenza virus outbreaks reported from the late 19th century to January 2013.

\begin{tabular}{|c|c|c|}
\hline Year & Subtype & Country \\
\hline 1878-1935 & $\mathrm{H} 7 ?$ & Italy - enzootic \\
\hline 1890-1930 & $\mathrm{H} 7 ?$ & Germany - enzootic \\
\hline 1922 & H7? & UK \\
\hline 1923-1945 & H7? & Egypt - enzootic \\
\hline 1924-1925 & $\mathrm{H} 7 ?$ & USA \\
\hline 1927 & H7? & Indonesia \\
\hline 1929 & $\mathrm{H} 7 ?$ & UK \\
\hline 1929 & H7? & USA \\
\hline 1959 & H5N1 & Scotland \\
\hline 1961 & H5N3 & South Africa \\
\hline 1963 & H7N3 & UK \\
\hline 1966 & H5N9 & Canada \\
\hline 1976 & H7N7 & Australia \\
\hline 1979 & H7N7 & UK \\
\hline 1979 & H7N7 & Germany \\
\hline 1983/1984 & H5N2 & USA \\
\hline 1983/1984 & H5N8 & Ireland \\
\hline 1985 & H7N7 & Australia \\
\hline 1991 & H5N1 & UK \\
\hline 1992 & H7N3 & Australia \\
\hline 1994/1995 & H5N2 & Mexico \\
\hline 1994 & H7N3 & Australia \\
\hline 1994 & H7N3 & Pakistan \\
\hline 1996 (ongoing) $^{\dagger}$ & H5N1 & Asia, Europe and Africa \\
\hline 1997 & H7N4 & Australia \\
\hline 1997 & H5N2 & Italy \\
\hline 1999 & H7N1 & Italy \\
\hline 2002 & H7N3 & Chile \\
\hline 2003 & H7N7 & Netherlands \\
\hline 2004 & H7N3 & Canada \\
\hline 2004 & H5N2 & USA \\
\hline 2004 & H5N2 & South Africa \\
\hline 2004 & H7N3 & Pakistan \\
\hline 2004 & H5N2 & Chinese Taipei \\
\hline 2005 & H7N7 & North Korea \\
\hline 2005/2006 & H5N2 & Zimbabwe \\
\hline 2007/2008 & H7N3 & Canada \\
\hline 2008 & H7N7 & UK \\
\hline 2009/2010 & H7N7 & Spain \\
\hline
\end{tabular}


Table 1. High-pathogenic avian influenza virus outbreaks reported from the late 19th century to January 2013 (cont.).

\begin{tabular}{|lll|}
\hline Year & Subtype & Country \\
\hline $2011 / 2012$ & H5N2 & South Africa \\
\hline 2012 & H7N7 & Australia \\
\hline 2012 & H5N2 & Chinese Taipei \\
\hline 2012 & H7N3 & Mexico \\
\hline 2012 & H7N1 & South Africa \\
\hline 2012 (ongoing) & H7N3 & Mexico \\
\hline $\begin{array}{l}\text { 'Since the emergence of the H5N1 high-pathogenic avian influenza virus in southern China and Hong Kong in 1996, an } \\
\text { unprecedented multitude of outbreaks has been reported. Moreover, in Bangladesh, China, Egypt, India, Indonesia and } \\
\text { Vietnam, the H5N1 high-pathogenic avian influenza viruses have become enzootic [101]. } \\
\text { Reported high-pathogenic avian influenza virus outbreaks were compiled from [11,101]. }\end{array}$ \\
\hline
\end{tabular}

influenza viruses (LPAIV) carry an HA cleavage site (HACS) with a motif of one basic amino acid, almost always consisting of an arginine. By stark contrast, all HPAIV carry a polybasic HACS. This difference in cleavage motifs determines which host protease is capable of cleaving HA0. Accordingly, the monobasic HACS motif is cleaved by tissue-restricted proteases such as TMPRSS2, HAT, matriptase, other trypsinlike proteases [30-35], and perhaps yet unidentified proteases, whereas the polybasic HACS is recognized by the ubiquitous proprotein convertase furin and related subtilases [36,37]. Such different tissue restriction of the host proteases entails (but is not sufficient for) distinct viral tissue tropisms. Thus, LPAIV are mostly confined to the digestive or respiratory tracts [38-40], whereas HPAIV exhibit a very broad tissue tropism afflicting many organs, including the CNS, often considered the prime cause of death in infected birds (Figure 1) [1-4].

Beside the polybasic HACS, HPAIV differ from LPAIV in that they are restricted to the HA serotypes $\mathrm{H} 5$ and $\mathrm{H} 7$, two of $16 \mathrm{HA}$ serotypes known in avian influenza viruses $[1,41,42]$. While all 16 HA serotypes are prevalent in LPAIV with some preferences for certain avian species [43], only $\mathrm{H} 5$ and $\mathrm{H} 7$ are found both in low- and high-pathogenic strains (FIGURE 2).

\section{Origin \& evolution of HPAIV}

All HPAIV have evolved from low-pathogenic precursors that circulate in the global population of wild aquatic birds, due to an extension of the HACS by an insertion mutation coding for a stretch of basic amino acids. LPAIV closely related to the subsequent HPAIV were detected in domestic poultry weeks or months prior to HPAIV outbreaks, such as in Pennsylvania 1983 [44,45], Italy 1999 [46,47], The Netherlands 2003 [15] or Chile 2004 (Figure 1) [48]. Therefore, it appears that, at least in those instances, the evolution from LPAIV to HPAIV took place in gallinaceous birds.

Remarkably, the HACS of HPAIV differ in their amino acid composition, proving independent mutation events (Figure 1) [44,48-50]. Furthermore, phylogenetic analyses indicated that the HA of HPAIV do not form unique lineages [51]. For a few HPAIV, the inserted nucleotide sequence encoding multiple basic amino acids was found to originate from the viral nucleoprotein or matrix protein genes (Figure 1) $[48,49]$ or host ribosomal 28S RNA [52], indicating RNA recombination. On the other hand, the creation of the polybasic cleavage site was hypothesized to be due to polymerase slippage during genome replication at purine-rich regions preceding the HACS coding sequence [53]. It should be emphasized, however, that in most HPAIV the mechanism for the insertion mutations is still elusive.

\section{The polybasic HA cleavage site is the prime virulence determinant of HPAIV}

The relevance of the polybasic HACS for virulence of HPAIV in mammals and chickens was addressed by experimental conversion into a monobasic motif. In mice and ferrets, HPAIV-derived mutants with a monobasic cleavage site display a considerably reduced level of virulence, demonstrated by less severe symptoms and confinement of viral replication to the respiratory tract [54-56]. In chickens, the experimental removal of the polybasic HACS from HPAIV led to an even more pronounced reduction of virulence, resulting in a seemingly avirulent phenotype of the HACS mutants with a monobasic cleavage motif [57,58]. Thus, the polybasic HACS is the dominant virulence determinant in HPAIV with regard to induction of disease in chickens. In HPAIV-derived monobasic HACS mutants, other still partially 


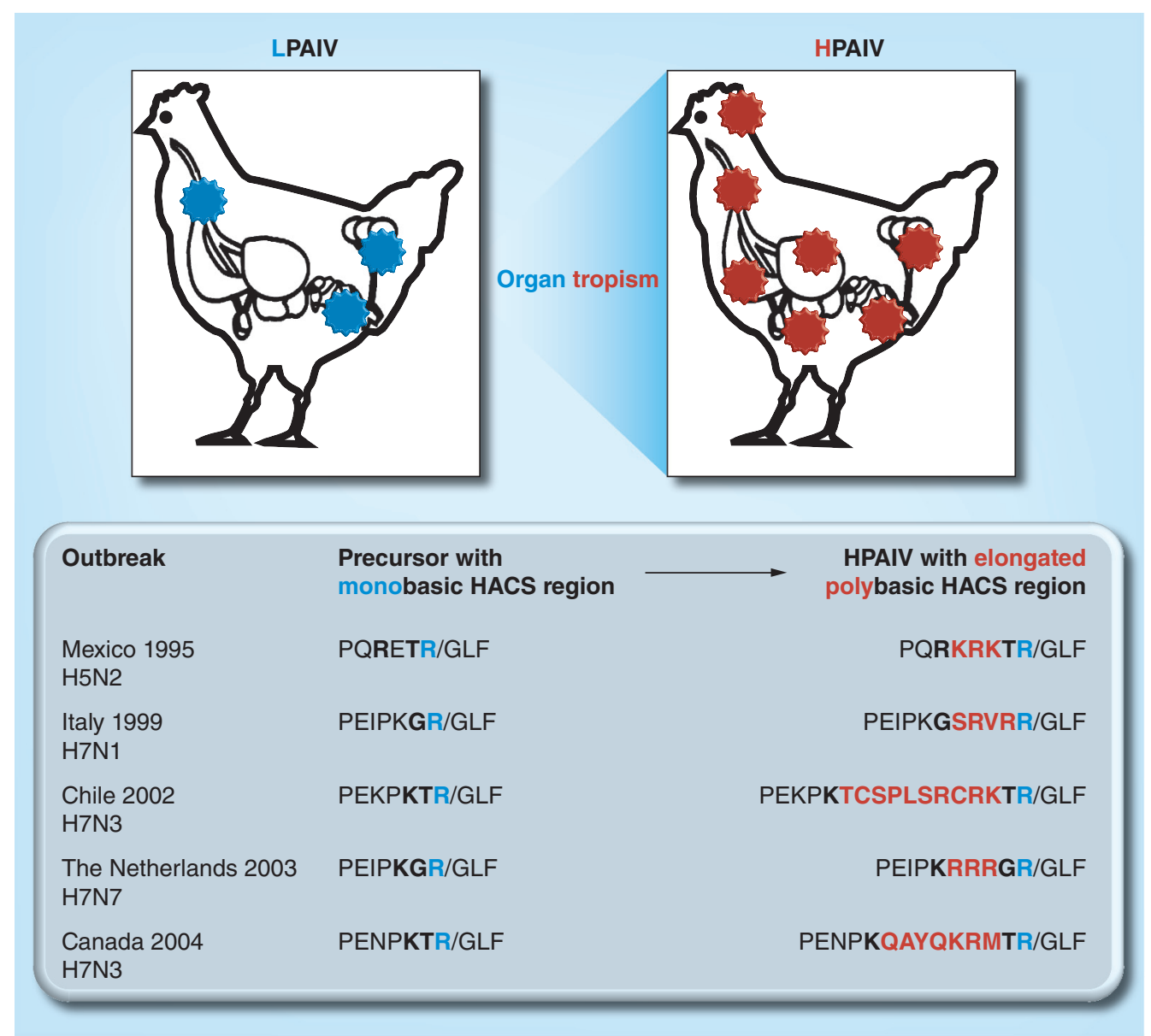

Figure 1. Evolution of high-pathogenic avian influenza virus from low-pathogenic avian influenza virus. In low-pathogenic strains, the monobasic HACS (containing either arginine or, rarely, lysine in position 1 of the HACS) is associated with low virulence in chickens (blue). Highly pathogenic strains originate from low-pathogenic precursors by acquisition of an elongated polybasic HACS due to an insertion mutation, leading to high virulence (red). The amino acid residues in the precursor hemagglutinin flanking the insertion are printed in bold. Whereas in most cases the mechanism of this mutational insertion has remained uncertain, some HPAIV have acquired their polybasic HACS by recombination with host or viral RNA. Accordingly, the Chile and Canada strains carry elongated HACS regions with fragments originating from the NP or M genes [48,49].

HACS: Hemagglutinin cleavage site; HPAIV: High-pathogenic avian influenza virus;

LPAIV: Low-pathogenic avian influenza virus.

unknown virulence determinants that remained after mutagenesis of only the HACS region, are dormant. Thus, at the present level of knowledge, any low-pathogenic strain of the $\mathrm{H} 5$ or $\mathrm{H} 7$ serotype has to be considered a potential HPAIV precursor. In summary, those studies showed that the polybasic HACS is the key virulence determinant of HPAIV.

\section{Introduction of a polybasic HA cleavage site into LPAIV does not inevitably result in a highly pathogenic phenotype}

In nature the emergence of HPAIV is restricted to serotypes $\mathrm{H} 5$ and H7. However, the molecular basis for this restriction is unclear. To distinguish between the compatibility of a polybasic cleavage site with $\mathrm{H} 5 / \mathrm{H} 7 \mathrm{HA}$ only and/or a unique predisposition of those two serotypes for insertion mutations, we introduced a polybasic HACS into the HA of non- $\mathrm{H} 5 / \mathrm{H} 7$ serotypes. Integration of a polybasic HACS into the HA of several LPAIV, namely a duck $\mathrm{H} 3$, duck $\mathrm{H} 4$ or chicken H9 strain [59-61], resulted in the immediate transformation to an in vitro phenotype resembling HPAIV. These viruses replicated in cell culture independently of the presence of the protease trypsin, exogenously added to activate monobasic HA0 of LPAIV, and also produced plaques without the need for an exogenous protease. Thus, in these parameters they were indistinguishable from natural HPAIV. However, none of those viruses exhibited a highly 
pathogenic phenotype in chickens, separating the in vitro traits from the in vivo phenotype. Remarkably, an engineered polybasic HACS mutant of a low-pathogenic H5N1 isolated from teal, which as an LPAIV of H5 serotype has to be considered a potential HPAIV precursor, did not display high virulence either [62]. By contrast, insertion of a polybasic HACS into an H6 LPAIV isolated from mallards resulted in a virulent phenotype [63], although this was not as highly pathogenic as natural $\mathrm{H} 5$ or $\mathrm{H} 7$ HPAIV. Interestingly, four naturally occurring avian strains have been described that carry a polybasic HACS, but demonstrate low virulence in chickens [64]. Thus, insertion of a polybasic HACS, although it represents the dominant virulence marker in natural HPAIV, is not sufficient to confer a highly pathogenic phenotype on any LPAIV, although it may suffice in certain viral backgrounds. Moreover, the low-pathogenic precursor of the H5N2 HPAIV leading to the fowl plague outbreak in 1983 in Pennsylvania carried a polybasic HACS that was prevented from furin cleavage by nearby

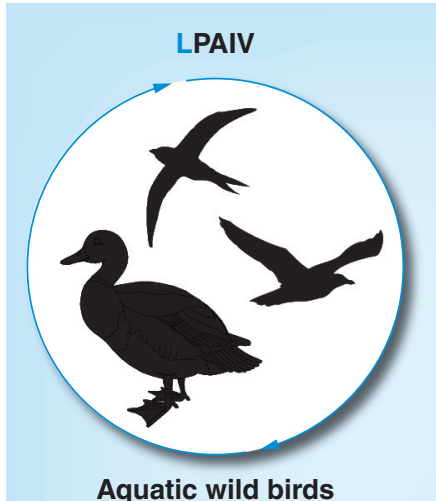

Aquatic wild birds

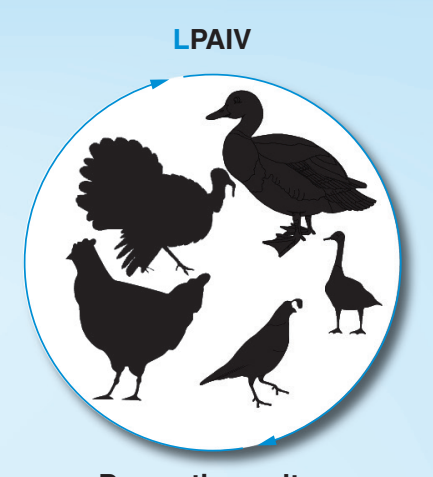

Domestic poultry

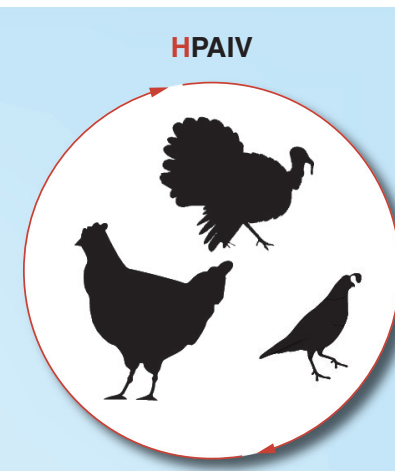

Gallinaceous domestic poultry

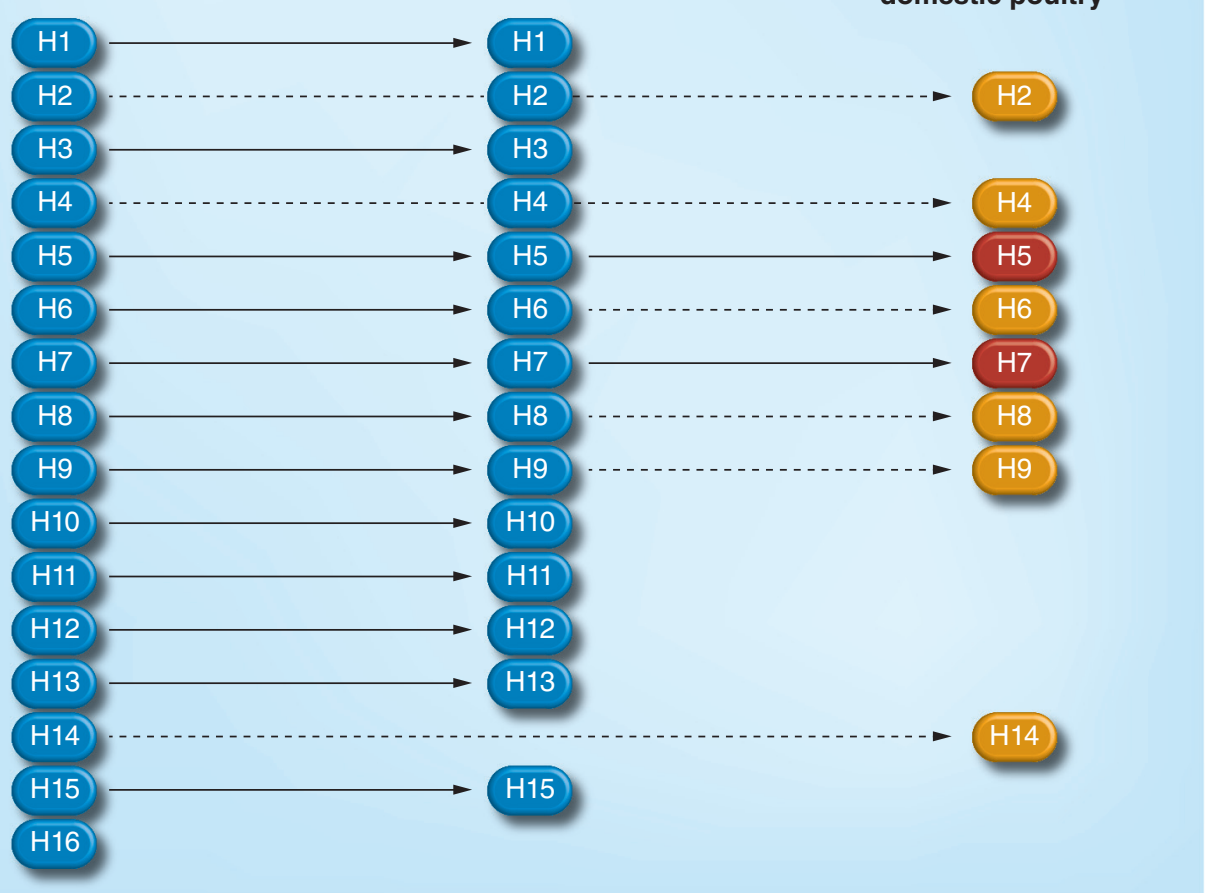

Figure 2. Hemagglutinin serotype prevalence in different avian reservoirs. LPAIV (blue) with serotypes $\mathrm{H} 1-\mathrm{H} 16$ are maintained in aquatic wild birds (left panel) and domestic poultry (middle panel) comprising Anseriformes and Galliformes [76,77], in which they might undergo prior host adaptation, facilitating later evolution into HPAIV. Natural HPAIV (right panel) were found predominantly in gallinaceous domestic birds (and occasionally in wild birds), originate from low-pathogenic precursors and are restricted to the hemagglutinin (HA) serotypes $\mathrm{H} 5$ and $\mathrm{H} 7$ (red). However, experimental HPAIV (orange) carrying a non-H5/H7 HA with an engineered polybasic HA cleavage site exhibit a lethal phenotype in chickens, as well [60-63]. H14 and H16 have not been detected in domestic poultry to date.

HPAIV: High-pathogenic avian influenza virus; LPAIV: Low-pathogenic avian influenza virus. 
site-specific glycosylation. The subsequent loss of that glycosylation site by mutation resulted in a high-pathogenic virus [65]. On the other hand, prolonged passaging in cell culture in the absence of trypsin of an avian-like H7N7 virus from seal led to the spontaneous acquisition of a polybasic HACS accompanied by high virulence, especially in chickens [66]. These findings indicate that even LPAIV not isolated from gallinaceous poultry may be able to transform into an HPAIV upon acquisition of a polybasic HACS, whereas not every H5 or H7 LPAIV may serve as a HPAIV precursor without further adaptation.

\section{Reassortment studies reveal the existence of additional virulence determinants in HPAIV}

Earlier reassortment studies revealed that the immediate precursor of the Pennsylvania outbreak in 1983 carried virulence determinants in all viral proteins aside from the HA already including a polybasic HACS shielded by a carbohydrate attached to the stalk [45,67]. Remarkably, reassortment of two H5N1 HPAIV may result in decreased virulence [68]. Furthermore, the NS gene was shown to contribute to high pathogenicity in chickens [69]. Moreover, reassortants carrying the $H A$ gene from an H5 HPAIV with the other seven genes originating from either an H9 or H5 LPAIV showed transient, nonlethal disease in chickens, whereas reassortants with the reciprocal gene constellation (i.e., the LPAIV $\mathrm{H} 9$ or H5 HA with artificial polybasic HACS and the genetic background from an HPAIV), were lethal for chickens $[61,62]$. Therefore, virulence determinants in HPAIV exist beyond the essential polybasic HACS and reside both within the $H A$ gene and in the other gene segments. In addition, there might be several independent combinations of virulence determinants in different HPAIV strains. This trait renders any assessment of the risk of circulating $\mathrm{H} 5$ or $\mathrm{H} 7$ LPAIV becoming transformed into HPAIV very difficult.

\section{HA of serotypes other than H5 or H7 can support high virulence}

Experimental introduction of a polybasic HACS into an H6 LPAIV and generation of an HPAIV reassortant carrying an $\mathrm{H} 9 \mathrm{HA}$ with polybasic HACS resulted in a strikingly increased virulence for chickens $[61,63]$. However, with IPVI values of 1.40 and 1.23 , respectively, the level of virulence was still lower than those of natural H5 or H7 HPAIV, which specify IPVI values of above 2. To investigate whether HPAIV of other serotypes was also capable of supporting a highly pathogenic phenotype, a polybasic cleavage site was engineered into the HA of LPAIV with serotypes $\mathrm{H} 1, \mathrm{H} 2, \mathrm{H} 3, \mathrm{H} 4, \mathrm{H} 6, \mathrm{H} 8, \mathrm{H} 10, \mathrm{H} 11, \mathrm{H} 14$ or H15. Respective HA reassortants were generated by cotransfection with the genes from either a low-pathogenic H9N2 or a high-pathogenic H5N1 avian strain. Those recombinants that contained the engineered $\mathrm{H} 2, \mathrm{H} 4, \mathrm{H} 8$ or $\mathrm{H} 14$ genes in the HPAIV background were lethal in chickens and exhibited intravenous pathogenicity index values of 2.79, 2.37, 2.85 and 2.61, respectively, equivalent to naturally occurring $\mathrm{H} 5$ or H7 HPAIV. Thus, in the presence of a polybasic HACS, non-H5/H7 HA can support a high-pathogenic phenotype in the appropriate viral background, indicating the need for further adaptation. Hence, the observed restriction of natural HPAIV to serotypes $\mathrm{H} 5$ and $\mathrm{H} 7$ is likely due to their unique predisposition for acquisition of a polybasic HACS [60], but may not be absolute.

\section{Conclusion}

In light of our results that non-H5/H7 HPAIV can be generated experimentally $[60,61]$, it is conceivable that HPAIV with novel serotypes could emerge in the future. Until the late 1950s, known fowl plague viruses were invariably H7, while HPAIV with the serotype H5 appeared thereafter. Today, both $\mathrm{H} 7$ and $\mathrm{H} 5$ HPAIV occur independently all over the world (TABle 1). However, the molecular basis for the emergence of an HPAIV is still not fully understood. Previous observations suggest that the evolution of an LPAIV into HPAIV takes place in gallinaceous poultry prior to an HPAIV outbreak. Accordingly, prolonged circulation for weeks, or even months, of low-pathogenic precursor viruses was observed before emergence of an HPAIV. Since the acquisition of a polybasic HACS is due to an insertion mutation and, thus, occurs at considerable lower probabilities than any sequence of point mutations, virulence or host range determinants have to enable survival of those LPAIV in the chicken host. Such determinants, in addition to those acquired after the formation of a polybasic HACS, may comprise a lowered optimal $\mathrm{pH}$ to trigger fusion of the HA [70,71] and additional modifications $[59,62,68,69,72]$, such as a deletion within the NA stalk region [73-75]. Furthermore, in nature, a polybasic HACS has so far only been found in $\mathrm{HA}$ of the $\mathrm{H} 5$ or $\mathrm{H} 7$ serotypes. This HA serotype restriction 
of natural HPAIV points to a predisposition of the $\mathrm{H} 5 / \mathrm{H} 7 \mathrm{HA}$ for acquisition of a polybasic HACS. However, if additional virulence determinants in the HA and other genes are dormant in the absence of a polybasic HACS, the experimental introduction of a polybasic HACS can yield highly pathogenic viruses with HA serotypes other than $\mathrm{H} 5$ or $\mathrm{H} 7$. Thus, the emergence of HPAIV with novel serotypes is conceivable.

\section{Future perspective}

Previous experiments have revealed that beside the polybasic HACS, HPAIV carry virulence determinants within the $H A$ and other genes. For an evidence-based risk assessment of any given LPAIV, in particular those of the $\mathrm{H} 5$ and $\mathrm{H} 7$ serotypes, to transform into HPAIV, future studies should map those sites by generating single-gene reassortants between well-characterized LPAIV and HPAIV with and without polybasic HACS. In a subsequent step, the virulence determinants may be narrowed to single amino acid exchanges by investigating viruses with chimeric gene segments. Likely candidates for virulence determinants include changes affecting the $\mathrm{pH}$ stability of the HA [71] or the NA stalk deletion [73-75]. Above all, it should be considered that different combinations of virulence determinants within one viral genome might yield a highly pathogenic phenotype. Therefore, those studies will have to be performed with a multitude of HPAIV/LPAIV pairs. So far, most of the experimental work on HPAIV/LPAIV has centered on $\mathrm{H} 5$ serotypes. To obtain a comprehensive picture and, hopefully, deduce congruent evolutionary parameters, similar extensive studies also need to be performed with $\mathrm{H} 7$ viruses and with strains specifying other HA serotypes.

\section{Executive summary}

\section{High-pathogenic avian influenza viruses are a unique group among the influenza $A$ viruses}

- High-pathogenic avian influenza viruses (HPAIV) differ from low-pathogenic avian influenza viruses (LPAIV) by the presence of a polybasic hemagglutinin (HA) cleavage site (HACS).

- While there are 16 HA serotypes known in avian influenza virus strains, HPAIV are confined to the serotypes H5 and H7.

\section{Origin \& evolution of HPAIV}

- Circulating H5 or H7 LPAIV may evolve into HPAIV.

- The heterogeneous HACS motifs found in HPAIV indicate independent mutational events and suggest different mechanisms of acquisition of a polybasic HACS.

\section{A polybasic HA cleavage site is the prime virulence determinant}

- Experimental removal of the polybasic HACS from HPAIV invariably leads to a low-pathogenic phenotype in chicken.

- Unknown virulence determinants may be dormant in circulating LPAIV.

\section{Artificial introduction of a polybasic HACS into LPAIV}

- Experimental introduction of a polybasic HACS into LPAIV may not necessarily result in a highly pathogenic phenotype.

- In addition, avian strains with polybasic HACS but low virulence in chicken underline the requirement for further adaptation.

- LPAIV isolated from bird species other than chicken may be able to evolve into HPAIV.

\section{Reassortment studies with HPAIV}

- Circulating H5 or H7 LPAIV may immediately transform into HPAIV upon acquisition of a polybasic HACS.

- Reassortment studies revealed that besides the polybasic HACS, there are further virulence determinants in the $H A$ and the other genes, and that several combinations of virulence determinants in different viral strains may exist.

\section{HA of serotypes other than $\mathrm{H} 5$ or $\mathrm{H} 7$ can support high virulence}

- HA of serotypes other than H5 or H7 can support high virulence in the genetic background of an HPAIV. Thus, provided further adaptation, novel HPAIV with serotypes other than $\mathrm{H} 5$ or $\mathrm{H} 7$ could emerge in the future.

- The generation of functional non-H5/H7 HA with polybasic HACS suggests that the natural restriction of HPAIV to serotypes H5 and $\mathrm{H} 7$ may be due to a predisposition of the H5/H7 HA for an insertion mutation coding for a polybasic HACS.

\section{Future perspective}

- Identification of other virulence determinants residing in the HA or other genes, such as the neuraminidase, polymerase, nucleoprotein or NS genes should be carried out.

- Several HPAIV/LPAIV pairs should be studied.

- Future studies should elucidate the virulence potential of H7 LPAIV and the virulence determinants in H7 HPAIV.

- Evidence-based analysis of the risk for circulating LPAIV transforming into HPAIV should be performed. 


\section{Financial \& competing interests \\ disclosure}

The authors have no relevant affliations or financial involvement with any organization or entity with a financial interest in or financial conflict with the subject matter or materials discussed in the manuscript. This includes employment, consultancies, honoraria, stock ownership or options, expert testimony, grants or patents received or pending, or royalties.

No writing assistance was utilized in the production of this manuscript.

\section{Open Access}

This work is licensed under the Creative Commons Attribution-NonCommercial 3.0 Unported License. To view a copy of this license, visit http://creativecommons.org/licenses/ by-nc-nd/3.0/

\section{References}

Papers of special note have been highlighted as:

- of interest

.. of considerable interest

1. Alexander DJ. A review of avian influenza in different bird species. Vet. Microbiol. 74(1-2), 3-13 (2000).

2. Werner O. Classic fowl plague - a review. Berl. Munch Tierarztl. Wochenschr. 119(3-4), 140-150 (2006).

3. Swayne DE, Pantin-Jackwood M. Pathogenicity of avian influenza viruses in poultry. Dev. Biol. (Basel) 124, 61-67 (2006).

4. Swayne DE. Understanding the complex pathobiology of high pathogenicity avian influenza viruses in birds. Avian Dis. 51(Suppl. 1), 242-249 (2007).

5. Alexander DJ. Avian influenza. In: Manual of Diagnostic Tests \& Vaccines for Terrestrial Animals (6th Edition). World Organisation for Animal Health, France, 465-481 (2008).

6. Soda K, Asakura S, Okamatsu M, Sakoda Y, Kida H. H9N2 influenza virus acquires intravenous pathogenicity on the introduction of a pair of di-basic amino acid residues at the cleavage site of the hemagglutinin and consecutive passages in chickens. Virol. J. 8(1), 64 (2011).

7. Veits J, Romer-Oberdorfer A, Helferich D et al. Protective efficacy of several vaccines against highly pathogenic $\mathrm{H} 5 \mathrm{~N} 1$ avian influenza virus under experimental conditions. Vaccine 26(13), 1688-1696 (2008).

8. Rudolf M, Poppel M, Frohlich A et al. Longitudinal 2 years field study of conventional vaccination against highly pathogenic avian influenza $\mathrm{H} 5 \mathrm{~N} 1$ in layer hens. Vaccine 28(42), 6832-6840 (2010).

9. van der Goot JA, Koch G, de Jong MC, van Boven M. Quantification of the effect of vaccination on transmission of avian influenza (H7N7) in chickens. Proc. Natl Acad. Sci. USA 102(50), 18141-18146 (2005).

10. van der Goot JA, van Boven M, Koch G, de Jong MC. Variable effect of vaccination against highly pathogenic avian influenza (H7N7) virus on disease and transmission in pheasants and teals. Vaccine 25(49), 8318-8325 (2007)

11. Klenk HD, Matrosovich, MN, Stech J. Avian influenza: molecular mechanisms of pathogenesis and host range. In: Animal Viruses: Molecular Biology. Mettenleiter TC, Sobrino F (Eds). Caister Academic Press, UK, 253-303 (2007).

12. Subbarao K, Klimov A, Katz J et al. Characterization of an avian influenza A $(\mathrm{H} 5 \mathrm{~N} 1)$ virus isolated from a child with a fatal respiratory illness. Science 279(5349), 393-396 (1998).

13. Claas EC, Osterhaus AD, van Beek R et al. Human influenza A H5N1 virus related to a highly pathogenic avian influenza virus. Lancet 351(9101), 472-477 (1998).

14. van Kolfschooten F. Dutch veterinarian becomes first victim of avian influenza. Lancet 361(9367), 1444 (2003).

15. Fouchier RA, Schneeberger PM, Rozendaal FW et al. Avian influenza A virus (H7N7) associated with human conjunctivitis and a fatal case of acute respiratory distress syndrome. Proc. Natl Acad. Sci. USA 101(5), 1356-1361 (2004).

16. Puthavathana $\mathrm{P}$, Auewarakul $\mathrm{P}$, Charoenying PC et al. Molecular characterization of the complete genome of human influenza $\mathrm{H} 5 \mathrm{~N} 1$ virus isolates from Thailand. J. Gen. Virol. 86(Pt 2), 423-433 (2005)

17. de Jong MD, Simmons CP, Thanh TT et al. Fatal outcome of human influenza A (H5N1) is associated with high viral load and hypercytokinemia. Nat. Med. 12(10), 1203-1207 (2006).

18. Alexander DJ, Brown IH. History of highly pathogenic avian influenza. Rev. Sci. Tech. 28(1), 19-38 (2009).

19. Schaefer W. [Comparative sero-immunological studies of the viruses of influenza and classical fowl plague.] Z. Naturforsch. 10(B), 81-91 (1955).

20. International Committee on Taxonomy of Viruses. Virus Taxonomy: Ninth Report of the International Committee on Taxonomy of Viruses. King AMQ, Lefkowitz E, Adams MJ,
Carstens EB (Eds). Academic Press, London, UK (2012).

21. WHO. Expert committee on influenza, first report. World Health Organ. Tech. Rep. Ser. 6(64), 1-32 (1953).

22. McGeoch D, Fellner P, Newton C. Influenza virus genome consists of eight distinct RNA species. Proc. Natl Acad. Sci. USA 73(9), 3045-3049 (1976).

23. Ritchey MB, Palese P, Kilbourne ED. RNAs of influenza A, B, and C viruses. J. Virol. 18(2), 738-744 (1976).

24. Palese P, Shaw ML. Orthomyxoviridae: the viruses and their replication. In: Fields Virology (5th Edition). Knipe DM, Howley PM (Eds). Lippincott Williams \& Wilkins, PA, USA, 1647-1690 (2007)

25. Klenk HD, Rott R, Orlich M, Blodorn J. Activation of influenza A viruses by trypsin treatment. Virology 68(2), 426-439 (1975).

26. Lazarowitz SG, Choppin PW. Enhancement of the infectivity of influenza $A$ and $B$ viruses by proteolytic cleavage of the hemagglutinin polypeptide. Virology 68(2), 440-454 (1975).

27. Maeda T, Ohnishi S. Activation of influenza virus by acidic media causes hemolysis and fusion of erythrocytes. FEBS Lett. 122(2), 283-287 (1980).

28. Huang RTC, Wahn K, Klenk HD, Rott R. Fusion between cell membranes and liposomes containing the glycoprotein of influenza virus. Virology 104(2), 294-302 (1980).

29. White JM, Matlin K, Helenius A. Cell fusion by Semliki Forest, influenza, and vesicular stomatitis viruses. J. Cell. Biol. 89(3), 674-679 (1981).

30. Bottcher E, Matrosovich T, Beyerle M et al. Proteolytic activation of influenza viruses by serine proteases TMPRSS2 and HAT from human airway epithelium. J. Virol. 80(19), 9896-9898 (2006)

31. Bottcher-Friebertshauser E, Freuer C, Sielaff $\mathrm{F}$ et al. Cleavage of influenza virus hemagglutinin by airway proteases TMPRSS2 and HAT differs in subcellular localization and susceptibility to protease inhibitors. J. Virol. 84(11), 5605-5614 (2010).

32. Bertram S, Glowacka I, Blazejewska P et al. TMPRSS2 and TMPRSS 4 facilitate trypsinindependent spread of influenza virus in Caco-2 cells. J. Virol. 84(19), 10016-10025 (2010).

33. Baron J, Tarnow C, Mayoli-Nussle D et al. Matriptase, HAT and TMPRSS2 activate the hemagglutinin of $\mathrm{H} 9 \mathrm{~N} 2$ influenza A viruses. J. Virol. 87(3), 1811-1820 (2012).

34. Hamilton BS, Gludish DW, Whittaker GR. Cleavage activation of the human-adapted 
influenza virus subtypes by matriptase reveals both subtype and strain specificities. J. Virol. 86(19), 10579-10586 (2012).

35. Bertram S, Heurich A, Lavender $\mathrm{H}$ et al. Influenza and SARS-coronavirus activating proteases TMPRSS2 and HAT are expressed at multiple sites in human respiratory and gastrointestinal tracts. PLoS ONE 7(4), e35876 (2012).

36. Garten W, Bosch FX, Linder D, Rott R, Klenk HD. Proteolytic activation of the influenza virus hemagglutinin: the structure of the cleavage site and the enzymes involved in cleavage. Virology 115(2), 361-374 (1981).

37. Stieneke-Groeber A, Vey M, Angliker H et al. Influenza virus hemagglutinin with multibasic cleavage site is activated by furin, a subtilisin-like endoprotease. $E M B O J$. 11(7), 2407-2414 (1992).

- Evidence that furin activates the hemagglutinin (HA) of high-pathogenic avian influenza viruses (HPAIV).

38. Cox NJ, Subbarao K. Influenza. Lancet 354(9186), 1277-1282 (1999).

39. Kuiken T, Taubenberger JK. Pathology of human influenza revisited. Vaccine 26(Suppl. 4), D59-D66 (2008).

40. Taubenberger JK, Morens DM. The pathology of influenza virus infections. Annu. Rev. Pathol. 3, 499-522 (2008).

41. Schild GC, Newman RW, Webster RG, Major D, Hinshaw VS. Antigenic analysis of influenza $A$ virus surface antigens: considerations for the nomenclature of influenza virus. Brief review. Arch. Virol. 63(3-4), 171-184 (1980).

42. Fouchier RA, Munster V, Wallensten A et al. Characterization of a novel influenza $A$ virus hemagglutinin subtype (H16) obtained from black-headed gulls. J. Virol. 79(5), 2814-2822 (2005).

43. Munster VJ, Baas C, Lexmond P et al. Spatial, temporal, and species variation in prevalence of influenza A viruses in wild migratory birds. PLoS Pathog. 3(5), e61 (2007).

- Most comprehensive analysis of low-pathogenic avian influenza viruses (LPAIV) in wild birds.

44. Kawaoka Y, Webster RG. Evolution of the A/chicken/pennsylvania/83 (H5N2) influenza virus. Virology 146(1), 130-137 (1985).

45. Webster RG, Kawaoka Y, Bean WJ Jr. Molecular changes in A/chicken/ Pennsylvania/83 (H5N2) influenza virus associated with acquisition of virulence. Virology 149(2), 165-173 (1986).

46. Banks J, Speidel ES, Moore E et al. Changes in the haemagglutinin and the neuraminidase genes prior to the emergence of highly pathogenic $\mathrm{H} 7 \mathrm{~N} 1$ avian influenza viruses in Italy. Arch. Virol. 146(5), 963-973 (2001).

47. Capua I, Marangon S. The avian influenza epidemic in Italy, 1999-2000: a review. Avian Pathol. 29(4), 289-294 (2000).

48. Suarez DL, Senne DA, Banks J et al. Recombination resulting in virulence shift in avian influenza outbreak, Chile. Emerg. Infect. Dis. 10(4), 693-699 (2004).

49. Pasick J, Handel K, Robinson J et al. Intersegmental recombination between the haemagglutinin and matrix genes was responsible for the emergence of a highly pathogenic $\mathrm{H} 7 \mathrm{~N} 3$ avian influenza virus in British Columbia. J. Gen. Virol. 86(Pt 3), 727-731 (2005).

50. Garten W, Klenk HD. Cleavage activation of the influenza virus hemagglutinin and its role in pathogenesis. In: Avian Influenza. Klenk HD, Matrosovich MN, Stech J (Eds). Karger, Switzerland, 156-167 (2008).

51. Roehm C, Horimoto T, Kawaoka Y, Suss J, Webster RG. Do hemagglutinin genes of highly pathogenic avian influenza viruses constitute unique phylogenetic lineages? Virology 209(2), 664-670 (1995).

52. Khatchikian D, Orlich M, Rott R. Increased viral pathogenicity after insertion of a $28 \mathrm{~S}$ ribosomal RNA sequence into the haemagglutinin gene of an influenza virus. Nature 340 (6229), 156-157 (1989).

- First evidence that a polybasic HA cleavage site (HACS) can be acquired by recombination.

53. Perdue ML, Garcia M, Senne D, Fraire M. Virulence-associated sequence duplication at the hemagglutinin cleavage site of avian influenza viruses. Virus Res. 49(2), 173-186 (1997).

- Hypothesized that a polybasic HACS could be acquired by polymerase slippage during genome replication.

54. Gabriel G, Dauber B, Wolff T et al. The viral polymerase mediates adaptation of an avian influenza virus to a mammalian host. Proc. Natl Acad. Sci. USA 102(51), 18590-18595 (2005).

55. Schrauwen EJ, Herfst S, Leijten LM et al. The multibasic cleavage site in $\mathrm{H} 5 \mathrm{~N} 1$ virus is critical for systemic spread along the olfactory and hematogenous routes in ferrets. J. Virol. 86(7), 3975-3984 (2012).

56. Suguitan AL Jr, Matsuoka Y, Lau YF et al. The multibasic cleavage site of the hemagglutinin of highly pathogenic A/Vietnam/1203/2004 (H5N1) avian influenza virus acts as a virulence factor in a host-specific manner in mammals. J. Virol. 86(5), 2706-2714 (2012).
57. Horimoto T, Kawaoka Y. Reverse genetics provides direct evidence for a correlation of hemagglutinin cleavability and virulence of an avian influenza A virus. J. Virol. 68(5), 3120-3128 (1994).

58. Gohrbandt $S$, Veits J, Hundt J et al. Amino acids adjacent to the haemagglutinin cleavage site are relevant for virulence of avian influenza viruses of subtype H5. J. Gen. Virol. 92(Pt 1), 51-59 (2010).

59. Stech O, Veits J, Weber $S$ et al. Acquisition of a polybasic hemagglutinin cleavage site by a low-pathogenic avian influenza virus is not sufficient for immediate transformation into a highly pathogenic strain. J. Virol. 83(11), 5864-5868 (2009).

- First study demonstrating that the artificial introduction of polybasic HACS into a LPAIV may not yield a high-pathogenic phenotype, indicating the existence of further virulence determinants.

60. Veits J, Weber S, Stech O et al. Avian influenza virus hemagglutinins $\mathrm{H} 2, \mathrm{H} 4, \mathrm{H} 8$, and H14 support a highly pathogenic phenotype. Proc. Natl Acad. Sci. USA 109(7), 2579-2584 (2012).

- The generation of non-H5/H7 HPAIV suggests the possible emergence of HPAIV with novel HA serotypes.

61. Gohrbandt S, Veits J, Breithaupt A et al. $\mathrm{H} 9$ avian influenza reassortant with engineered polybasic cleavage site displays a highly pathogenic phenotype in chicken. J. Gen. Virol. 92(Pt 8), 1843-1853 (2011).

62. Bogs J, Veits J, Gohrbandt S et al. Highly pathogenic $\mathrm{H} 5 \mathrm{~N} 1$ influenza viruses carry virulence determinants beyond the polybasic hemagglutinin cleavage site. PLoS ONE 5(7), e11826 (2010).

63. Munster VJ, Schrauwen EJ, de Wit E et al. Insertion of a multibasic cleavage motif into the hemagglutinin of a low-pathogenic avian influenza H6N1 virus induces a highly pathogenic phenotype. J. Virol. 84(16), 7953-7960 (2010).

- Demonstrates that the artificial introduction of polybasic HACS into a LPAIV that was not isolated from gallinaceous poultry may yield a high-pathogenic phenotype in chickens.

64. Londt BZ, Banks J, Alexander DJ. Highly pathogenic avian influenza viruses with low virulence for chickens in in vivo tests. Avian Pathol. 36(5), 347-350 (2007).

-. Describes four natural avian strains with polybasic HACS but low virulence in chickens, indicating that further adaptation is required, paralleling the experimental studies. 
65. Kawaoka Y, Naeve CW, Webster RG. Is virulence of $\mathrm{H} 5 \mathrm{~N} 2$ influenza viruses in chickens associated with loss of carbohydrate from the hemagglutinin? Virology 139(2), 303-316 (1984).

66. Li SQ, Orlich M, Rott R. Generation of seal influenza virus variants pathogenic for chickens, because of hemagglutinin cleavage site changes. J. Virol. 64(7), 3297-3303 (1990).

67. Kawaoka Y, Webster RG. Interplay between carbohydrate in the stalk and the length of the connecting peptide determines the cleavability of influenza virus hemagglutinin. J. Virol. 63(8), 3296-3300 (1989).

68. Wasilenko JL, Lee CW, Sarmento L et al. $N P, P B 1$, and $P B 2$ viral genes contribute to altered replication of $\mathrm{H} 5 \mathrm{~N} 1$ avian influenza viruses in chickens. J. Virol. 82(9), 4544-4553 (2008).

69. Li Z, Jiang Y, Jiao P et al. The NS1 gene contributes to the virulence of $\mathrm{H} 5 \mathrm{~N} 1$ avian influenza viruses. J. Virol. 80 (22), 11115-11123 (2006).
70. Grambas S, Hay AJ. Maturation of influenza A virus hemagglutinin - estimates of the $\mathrm{pH}$ encountered during transport and its regulation by the M2 protein. Virology 190(1), 11-18 (1992).

71. DuBois RM, Zaraket $\mathrm{H}$, Reddivari $\mathrm{M}$ et al. Acid stability of the hemagglutinin protein regulates $\mathrm{H} 5 \mathrm{~N} 1$ influenza virus pathogenicity. PLoS Pathog. 7(12), e1002398 (2011).

72. Ma W, Brenner D, Wang Z et al. The NS segment of an H5N1 highly pathogenic avian influenza virus (HPAIV) is sufficient to alter replication efficiency, cell tropism, and host range of an H7N1 HPAIV. J. Virol. 84(4), 2122-2133 (2010).

73. Deshpande KL, Naeve CW, Webster RG. The neuraminidases of the virulent and avirulent A/chicken/Pennsylvania/83 (H5N2) influenza A viruses: sequence and antigenic analyses. Virology 147(1), 49-60 (1985).

74. Munier S, Larcher T, Cormier-Aline F et al. A genetically engineered waterfowl influenza virus with a deletion in the stalk of the neuraminidase has increased virulence for chickens. J. Virol. 84(2), 940-952 (2010).

75. Sorrell EM, Song H, Pena L, Perez DR. A 27-amino-acid deletion in the neuraminidase stalk supports replication of an avian $\mathrm{H} 2 \mathrm{~N} 2$ influenza $\mathrm{A}$ virus in the respiratory tract of chickens. J. Virol. 84(22), 11831-11840 (2010).

76. Alexander DJ. Report on avian influenza in the eastern hemisphere during 1997-2002. Avian Dis. 47(Suppl. 3), 792-797 (2003).

77. Senne DA, Suarez DL, Pedersen JC, Panigrahy B. Molecular and biological characteristics of $\mathrm{H} 5$ and $\mathrm{H} 7$ avian influenza viruses in live-bird markets of the northeastern United States, 1994-2001. Avian Dis. 47(Suppl. 3), 898-904 (2003).

\section{Website}

101. OIE. World Organisation for Animal Health. Update on highly pathogenic avian influenza in animals (types $\mathrm{H} 5$ and $\mathrm{H} 7$ ).

www.oie.int/animal-health-in-the-world/ update-on-avian-influenza/2011

(Accessed 18 January 2013) 